\title{
Perancangan Alat Kontrol Ketinggian Air Menggunakan Sensor Ultrasonik Berbasis SMS
}

\section{Designing Water Level Control Equipment Using SMS-Based Ultrasonic Sensors}

\author{
I Putu Eddy Aditya Harrischandra ${ }^{1 *}$, I Made Satriya Wibawa ${ }^{1}$, Nyoman Wendri ${ }^{1}$ \\ ${ }^{1}$ Jurus an Fisika, Fakultas Matematika dan Ilmu Pengetahuan Alam, Universitas Udayana, Kampus Bukit \\ Jimbaran, Badung, Bali, Indonesia 80361 \\ Email:eddyaditya56@gmail.com; satriya_wibawa@unud.ac.id;wendri@unud.ac.id
}

\begin{abstract}
Abs trak - Telah berhasil di rancang alat kontrol ketingian air menggunakan sensor ultrasonik berbasis Short Message Service (SMS). Alatyang dirancang menggunakan Arduino UNO ATmega328 sebagai mik rokontroler, sensor ultrasonik HC-SRO4 sebagai pengukur ketinggian air yang akan dikontrolmodul SMS SIM 800L sebagai penerima dan pengirimpesan dari alat rancangan menuju ponsel, LCD $16 \times 2$ sebagai tampilan serta modul Relay yang digunakan sebagai saklar otomatis yang akan mengaktifkan dan mematikan pompa air. Sebelummen guji alatrancangan dilakukankalibrasi pada sensor ultrasonik. Kalibrasi dilakukan untuk menyesuaikan nilai keluaran sensor dengan alat ukur referensi yang digunakan yaitu mistar dengan ketelitian $1 \mathrm{~mm}$. Hasil dari alat yang dirancang memiliki nilai presisi sebesar 99,99\% dan menunjukan bahwa alat rancangan telah bekerja dengan baik.
\end{abstract}

Kata kunci: Arduino UnoATmega328,mikrokontroler, sensor ultrasonik, SMS, SIM 800L, ketinggian air

\begin{abstract}
Abs tract - The controlled waterlevel using an ultrasonic sensor and Short Message Service (SMS) based has been successfullydeveloped. The developed tools using an Arduino UNO ATmega328 as microcontroller, an ultrasonic sensor for measuring the water level, SMS module SIM 800L to receiver and message sender from developed tools to handphone, $L C D 16 \times 2$ as a display and Relay module as automatic switch that would activate and deactivate the water pump. Before testing the developed tools, the ultrasonic sensor need to be calibrate. Calibration is carried out for adjusting the sensor's output with the measuring instrument which is a ruler with $1 \mathrm{~mm}$ precision. The result of the developed tools has precision value $99.99 \%$ and then showing the developed tools worked well.
\end{abstract}

Key words: Arduino UnoATmega328, microcontroller, ultrasonic sensor, SMS, SIM 800L, water level

\section{Pendahuluan}

Air adalah salah satu sumber daya yang mendukung keberlangsungan hidup manusia dan mahluk hidup lainnya, yang merupakan elemen utama kehidupan yang berkelanjutan. Banyak orang berpikir bahwa air adalah sumber daya alam yang tidak terbatas, walaupun sebenarnya hanya beberapa persen dari semua air yang tersedia di bumi ini berupa air bersih yang dapat dimanfaatkan oleh manusia [1].

Seiring perkembangan jaman, manusia membuat tangki air untuk menampung air yang bertujuan untuk cadangan air jika suatu saat terjadi gangguan yang menyebabkan terganggunya distribusi air, seperti mesin pompa air mengalami gangguan, mengeringnya sumber air bersih serta perusahaan penyedia air bersih mengalami gangguan yang mengakibatkan tidak adanya pasokan air bersih ke rumah. Tetapi penggunaan tangki air terdapat suatu masalah yaitu pengguna tidak mengetahui ketinggian air dalam tangki, apakah tangki dalam keadaan kosong atau penuh, sehingga dirancang sebuah alat kontrol ketinggian air secara otomatis [2].

Perancangan sistem kontrol ketinggian air telah banyak dilakukan, salah satunya merancang sistem kontrol ketinggian air dengan prinsip kerja menentukan batas minimal serta batas maksimal ketinggian air pada tangki, sehingga ketika air mencapai batas minimal ketinggian, maka mesin pompa air akan on, dan ketika ketinggian air mencapai batas maksimal, maka mesin pompa air akan off. Berdasarkan dari perancangan alat tersebut, maka dilaksanakan penelitian tentang "perancangan alat kontrol ketinggian air menggunakan sensor ultrasonik berbasis SMS". Alat tersebut diharapkan mampu mengontrol ketinggian air dengan tujuan menghemat penggunaan air serta listrik. Alat pengontrol ketinggian air ini terdiri dari 
sensor sebagai input, mikrokontroler Arduino Uno sebagai proses, modul relay sebagai switch serta modul SIM800L sebagai pengirim serta penerima sms.

Kelebihan alat yang dirancang dibandingkan alat yang sudah ada adalah penggunaan SMS sebagai kontrol Setpoint atau batas ketinggian air sehingga pengguna dapat mengontrol sendiri ketinggian air yang dikehendaki melalui SMS. Juga dapat langsung memonitoring tinggi air pada tangki melalui SMS, hal ini berbeda dari alat yang sudah ada, dimana batas maksimal ketinggian air sudah diatur pada program, sehingga pengguna tidak dapat mengatur ketinggian air sesuai kebutuhannya. Dengan kelebihan tersebut, diharapkan alat rancangan dapat bermanfaat bagi masyarakat.

\section{Landasan Teori}

\subsection{Short message service (SMS)}

Pengiriman SMS dari dan ke Personal Chat (PC) perlu dilakukan terlebih dahulu koneksi ke Short Message Service Center (SMSC) [3]. Koneksi PC ke SMSC adalah dengan menggunakan terminal berupa GSM modem ataupun ponsel yang terhubung dengan PC. Saat menggunakan ponsel, SMS yang mengalir dari atau ke SMSC harus berbentuk Protocol Data Unit (PDU). PDU berisi bilangan-bilangan heksadesimal yang mencerminkan bahasa I/O (kode). PDU sendiri terdiri atas beberapa bagian yang berbeda antara mengirim dan menerima SMS dari SMSC. Format data PDU ini dikirimkan ke PC dalam bentuk teks (string) yang menunjukkan nilai heksadesimalnya. Jadi saat ponsel mengirim data heksadesimal F, maka yang diterima oleh PC adalah teks F [4].

Untuk setiap pengiriman SMS, diperlukan data baku sesuai penetapan dokumen spesifikasi dari organisasi European Telecommunication Standards Institute (ETSI), pada dokumen spesifikasi GSM 03.04 dan GSM 03.38. Format SMS dibagi menjadi beberapa segmen data di mana setiap segmen memiliki maksud dan spesifikasi. Segmen tersebut adalah nomor SMS center, nomor telepon tujuan, byte untuk keperluan seting sms, dan yang terpenting adalah isi pesan SMS yang telah diubah dalam bentuk PDU. Untuk dapat mengirimkan atau upload data SMS ke ponsel dan memerintahkan ponsel untuk mengirimkan data SMS, diperlukan instruksi AT yaitu: "AT+CMGS=" Sebagai contoh, dengan mengirimkan perintah "AT $+\mathrm{CMGS}=21^{c e}$, maka isi pesan maksimum adalah 21 karakter dan ponsel akan merespons perintah dengan symbol " $>$ "e atau $\$ 21$ yang baru [5].

\subsection{Modul SIM800L}

SIM800L adalah modul SIM yang digunakan pada penelitian ini. Modul SIM800L GSM/GPRS adalah bagian yang berfungsi untuk berkomunikasi antara pemantau utama dengan Handphone. ATCommand adalah perintah yang dapat diberikan modem GSM/CDMA seperti untuk mengirim dan menerima data berbasis GSM/GPRS, atau mengirim dan menerima SMS [6]. SIM800L GSM/GPRS dikendalikan melalui perintah AT. AT+Command adalah sebuah kumpulan perintah yang digabungkan dengan karakter lain setelah karakter "AT"e yang biasanya digunakan pada komunikasi serial. Dalam penelitian ini ATcommand digunakan untuk mengatur atau memberi perintah modul GSM/CDMA. Perintah ATCommand dimulai dengan karakter "AT" atau "at" dan diakhiri dengan kode (0x0d). Bentuk fisik Modul SIM800L dapat dilihat pada Gambar 1 [7].

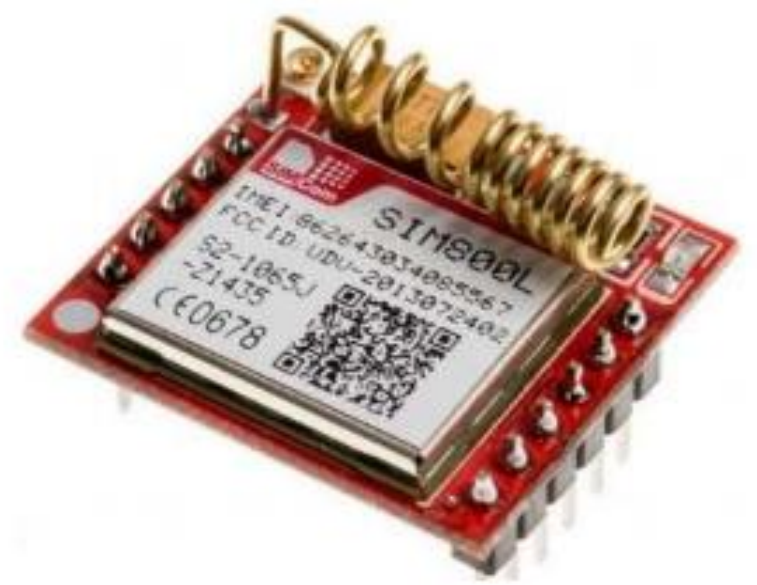

Gambar 1. Bentuk fisik SIM800L [8]. 
Modem GSM adalah sebuah perangkat elektronik yang berfungsi sebagai alat pengirim dan penerima pesan SMS. Tergantung dari tipenya, tapi umumnya alat ini berukuran cukup kecil, ukuran sama dengan pesawat telepon seluler GSM. Sebuah modem GSM terdiri dari beberapa bagian, di antaranya adalah lampu indikator, terminal daya, terminal kabel ke komputer, antena dan untuk meletakkan kartu SIM.

\subsection{ATmega328}

ATmega328 adalah micro controller keluaran Atmel yang merupakan anggota dari keluarga AVR 8-bit. Mikro kontroller ini memiliki kapasitas flash (program memory) sebesar $32 \mathrm{~Kb}$ (32.768 bytes), memori (static RAM) $2 \mathrm{~Kb}$ (2.048 bytes), dan EEPROM (non-volatile memory) sebesar 1024 bytes. Kecepatan maksimum yang dapat dicapai adalah $20 \mathrm{MHz}$. Rancangan khusus dari keluarga prosesor ini memungkinkan tercapainya kecepatan eksekusi hingga 1 cycle per instruksi untuk sebagian besar instruksinya, sehingga dapat dicapai kecepatan mendekati 20 juta instruksi per detik. ATMega328 adalah prosesor yang kaya fitur. Dalam chip yang dipaketkan dalam bentuk DIP-28 ini terdapat 20 pin Input/Output (21 pin bila pin reset tidak digunakan, 23 pin bila tidak menggunakan oskilator eksternal), dengan 6 di antaranya dapat berfungsi sebagai pin ADC (analog-to-digital converter), dan 6 lainnya memiliki fungsi PWM (pulse width modulation). Mikrokontroler ini diproduksi oleh atmel dari seri AVR. Untuk seri AVR ini banyak jenisnya, yaitu ATmega328, ATmega8535, Mega8515, dan Mega16 [9].

\subsection{Sensor Ultrasonik}

Pada perancangan alat kontrol ketinggian air menggunakan sensor ultrasonik berbaisis SMS, sensor ultrasonik yang digunakan adalah sensor ultrasonik HC-SR04. Sensor ultrasonik HC-SR04 memiliki frekuensi $40 \mathrm{KHz}$ dengan jarak jangkauan antara $2 \mathrm{~cm}-400 \mathrm{~cm}$. Sensor ultrasonik dapat digunakan untuk mengukur jarak antara penghalang dan sensor. Bentuk fisik HC-SR04 seperti terlihat pada Gambar 2 [10].

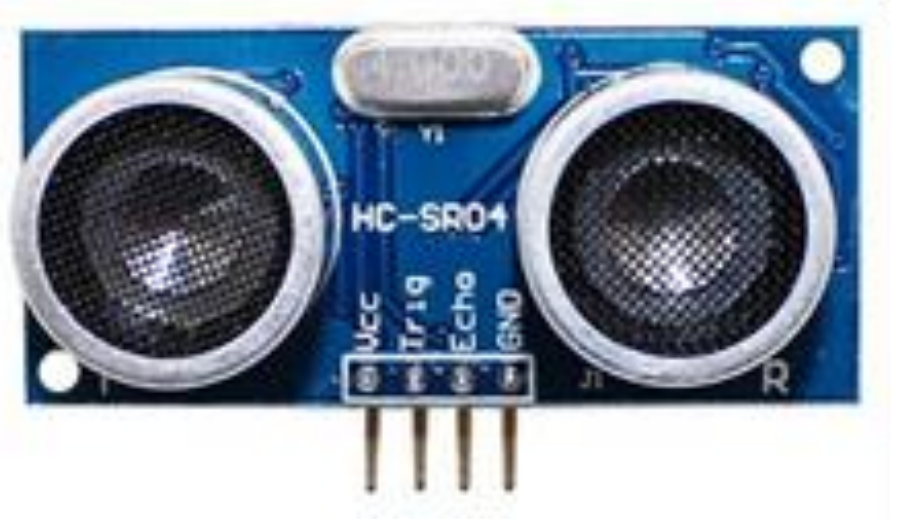

Gambar 2. Bentuk fisik sens or ultras onik HC-SR04 [11].

Sensor HC-SR04 memiliki dua komponen utama yaitu ultrasonik transmitter dan ultrasonik receiver. Fungsi dari ultrasonik transmitter adalah memancarkan gelombang ultrasonik dengan frekuensi sebesar $40 \mathrm{KHz}$, sedangkan ultrasonik receiver menangkap hasil pantulan gelombang ultrasonik yang mengenai suatu objek [11].

\subsection{Arduino Uno}

Pada penelitian ini digunakan Mikrokontroler ATmega328 yang telah dipasang pada Arduino Uno. Arduino Uno adalah Arduino board yang menggunakan mikrokontroler ATMega328. Bentuk dari Arduino Uno ditunjukkan pada Gambar 3.

Arduino Uno memiliki 14 pin digital (6 pin dapat digunakan sebagai output PWM (pulse width modulation)) 6 input analog, sebuah $16 \mathrm{MHz}$ osilator kristal, sebuah koneksi USB (Universal Serial $B u s$ ), sebuah konektor sumber tegangan, sebuah header ICSP, dan sebuah tombol reset. Arduino Uno memuat segala hal yang dibutuhkan untuk mendukung sebuah mikrokontroler [12]. Hanya dengan menghubungkan ke sebuah komputer melalui USB atau memberikan tegangan DC dari baterai atau adaptor AC ke DC sudah dapat membuatnya bekerja. Arduino Uno menggunakan ATMega328 yang diprogram sebagai USB to serial converter untuk komunikasi serial ke komputer melalui port USB. 
Untuk 7 membuat program, pengguna dapat menggunakan software Arduino Integrated Developtment Enviroenment (IDE) [13].

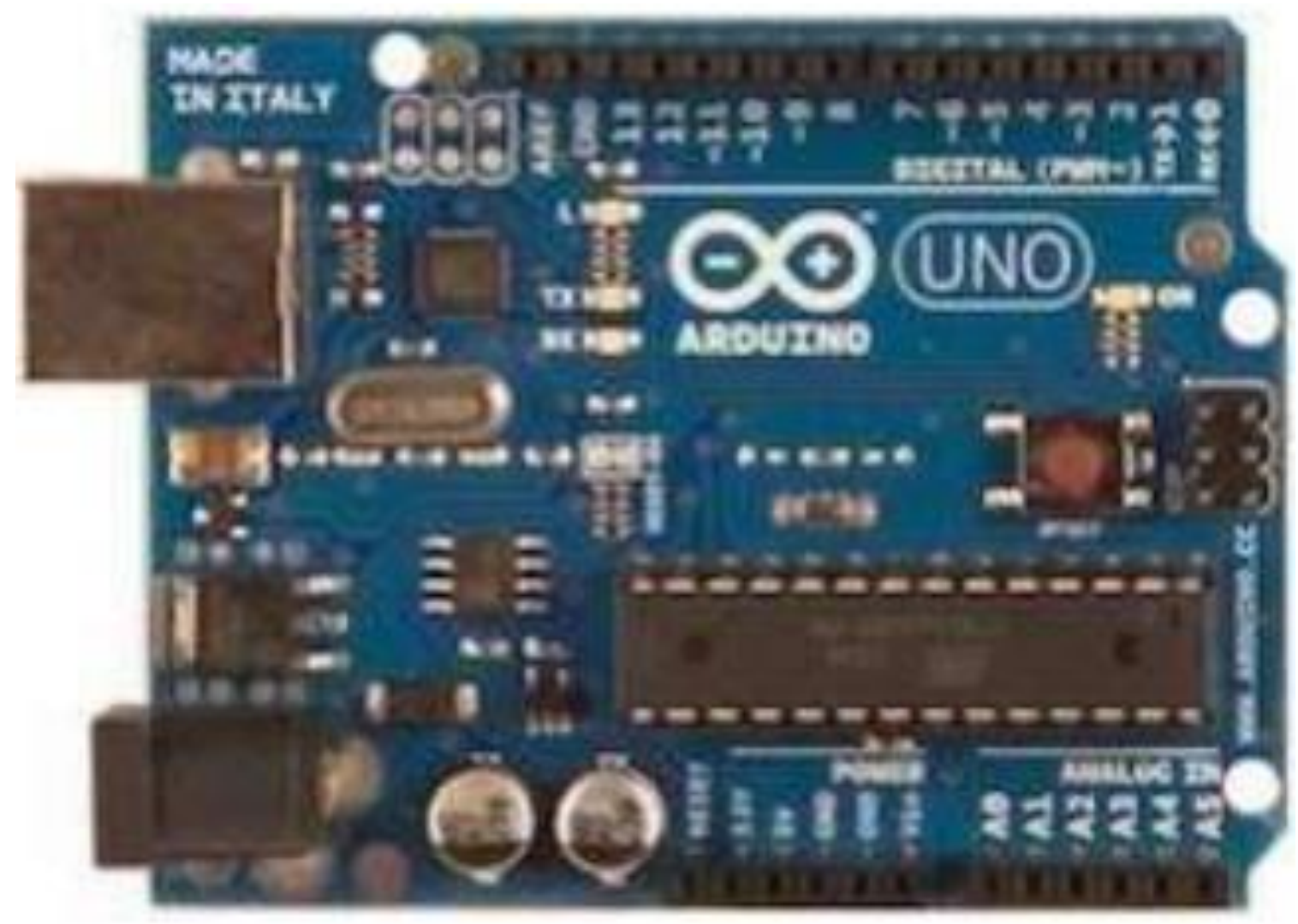

Gambar 3. Arduino Uno [12].

Arduino Uno memuat segala hal yang dibutuhkan untuk mendukung sebuah mikrokontroler. Hanya dengan menghubungkan ke sebuah komputer melalui USB atau memberikan tegangan DC dari baterai atau adaptor AC ke DC sudah dapat membuatnya bekerja [13].

\section{Metode Penelitian}

Penelitian dan perancangan alat kontrol ketinggian air pada tangki menggunakan sensor ultrasonik berbasis SMS dilaksanakan di Laboratorium Elektronika dan Instrumentasi, Program Studi Fisika, Fakultas Matematika dan Ilmu Pengetahuan Alam, Universitas Udayana, Bukit Jimbaran. Waktu penelitian dan perancangan dilakukan dari bulan Oktober tahun 2020 sampai dengan bulan Mei tahun 2021.

\subsection{Alat dan bahan}

Alat-alat yang digunakan untuk merancang alat kontrol ketinggian air pada tangki menggunakan sensor ultrasonik berbasis SMS, yaitu Komputer/leptop, Kabel USB Arduino Uno, Solder, Timah, Penyedot timah, Obeng, Pinset, Gergaji besi dan Lem pipa. Sedangkan bahan yang digunakan, yaitu Sensor ultrasonik HC-SR04, Arduino Uno, Kabel male-female, Kabel male-male, Kabel pelangi, Model tangka dari pipa PVC dengan ketinggian $65 \mathrm{~cm}$ berdiameter 11,4 cm, LCD, Adaptor $12 \mathrm{~V} \mathrm{1,5} \mathrm{A,} \mathrm{Modul}$ SIM800L, Modul relay 5 V, Project board, Air dan Bejana penampung air.

\subsection{Alur penelitian}

Berikut adalah diagram alir alat kontrol ketinggian air pada tangka menggunakan sensor ultrasonik dapat di lihat pada Gambar 4. 


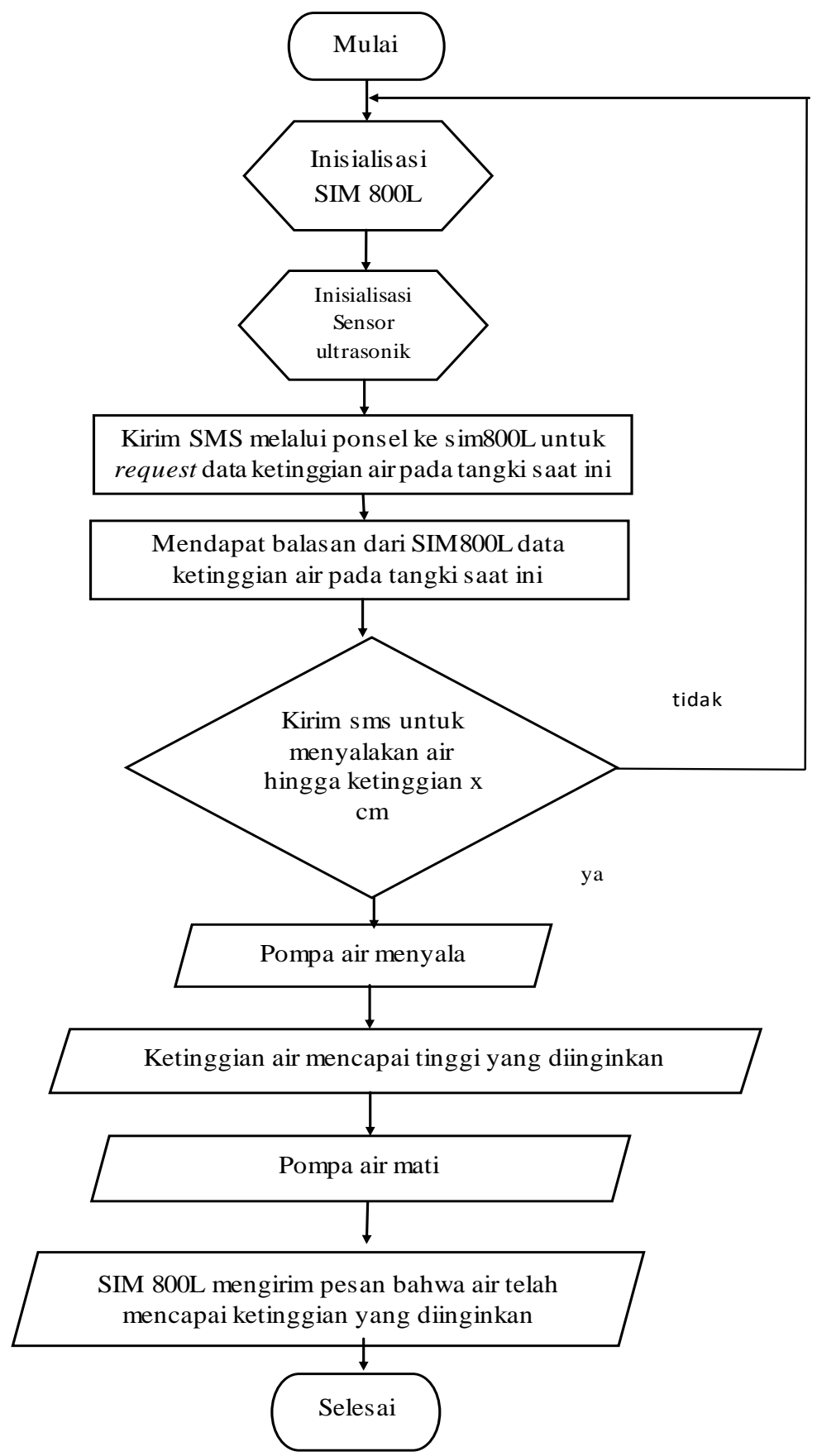

Gambar 4. Diagram alir alat kontrol ketinggian air pada tangka menggunakan sensor ultrasonik.

\section{Hasil Dan Pembahasan}

4.1 Hasil rancangan alat ukur

Telah berhasil dirancang alat kontrol ketinggian air menggunakan sensor ultrasonik berbasis SMS dengan metode kalibrasi dapat dilihat pada Gambar 5. Adapun uraian singkat dari fungsi masing-masing komponen utama alat kontrol ketinggian air berbasis sms, yang ditunjukkan pada Gambar 5, sebagai berikut. 


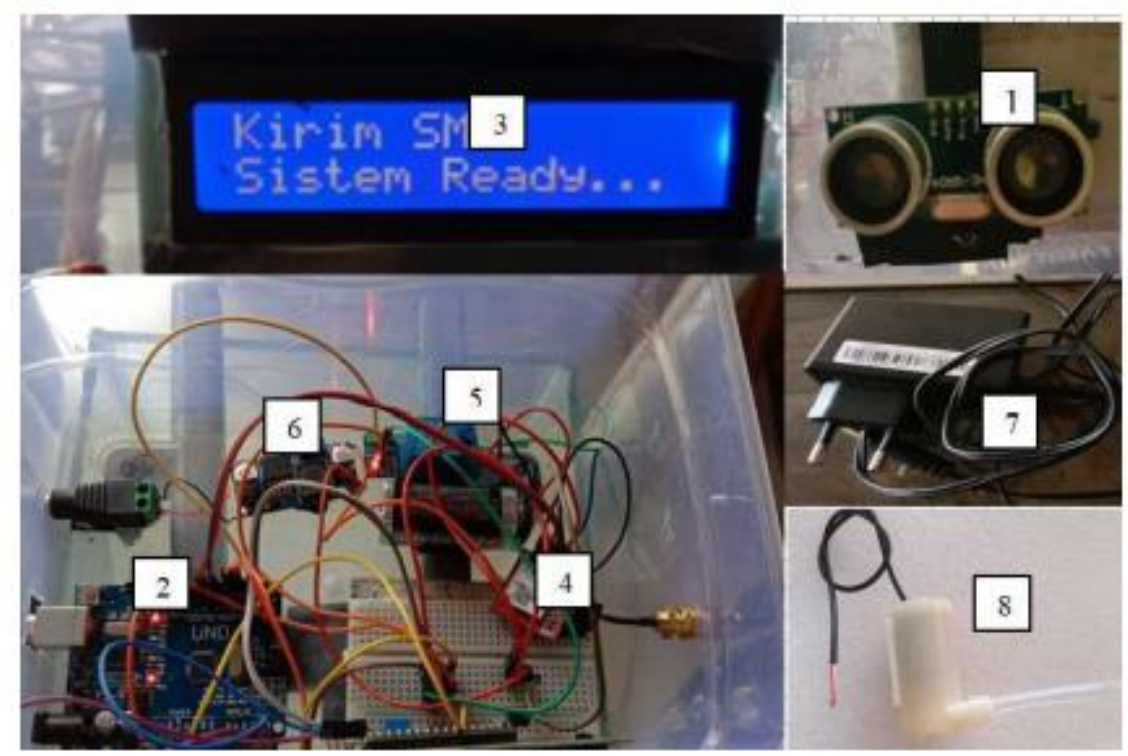

Gambar 5. Alat control ketinggian air berbasis SMS. 1) Sensor ultrasonik HC-SR04 sebagai sensor ketinggian air, 2) Rangkaian sistem minimum Arduino Uno sebagai mikrokontroler, 3) Modul LCD, berfungsi untuk menampilkan data yang terukur, dalampenelitian ini data yang terukur adalah ketinggian air, 4) Modul SMS SIM 800L berfungsi untuk mengirim dan menerima SMS, 5) Modul Relay 5V berfungsi sebagai saklar, 6) Modul Step-down LM2596DC-DC berfungsi sebagai menurunkan tegangan dari adaptor menuju modul SMS SIM 800L, 7) Adaptor 12 V sebagai sumber daya lis trik yang dialirkan kepada modul SMS SIM 800L, dan 8) Pompa air submerge.

\subsection{Aplikasi pengujian alat pada ketinggian air pada tangki}

Dilakukan pengujian alat rancangan dengan mengukur ketinggian air pada tangki yang telah disediakan. Alat rancangan diuji dengan cara memberikan perintah pesan teks (SMS) berupa set point yang dikirim melalui ponsel menuju nomor kartu prabayar yang digunakan pada alat rancangan. Ketika alat rancangan menerima SMS yang berisi perintah set point ketinggian air maka pompa air akan aktif dan mengalirkan air dari sumber air menuju tangki air hingga ketinggian air pada tangki mencapai ketinggian yang diperintahkan set point. Data pengamatan ditampikan dalam bentuk grafik seperti tampak pada Gambar 6. Gambar 6 memperlihatkan grafik antara ketinggian air rata-rata yang dibaca alat rancangan terhadap alat ukur referensi

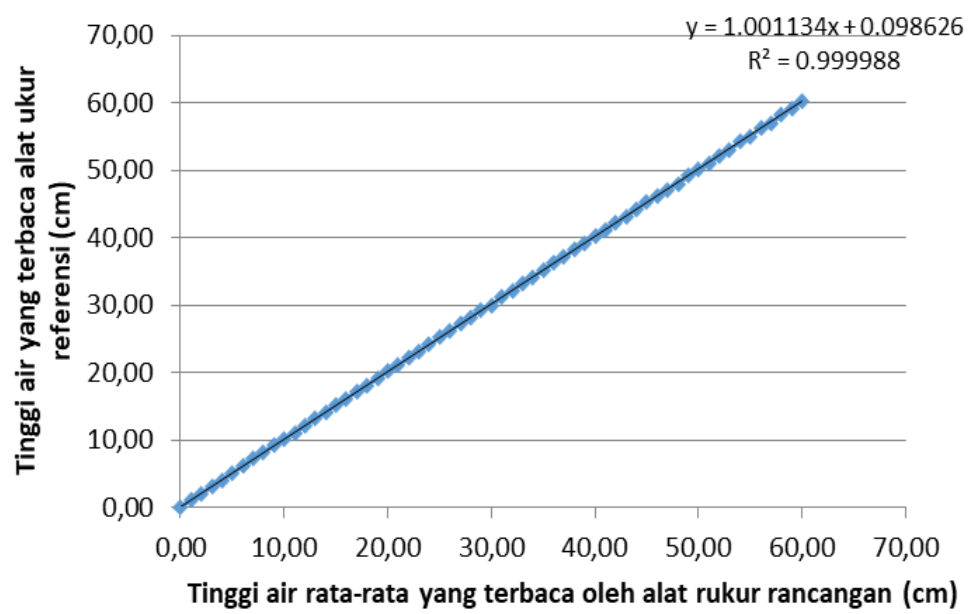

Gambar 6. Gambar grafik kolerasi ketinggian air terukur oleh alat rancangan terhadap alat ukur referensi.

Dari grafik diatas didapatan koefisien determinasi $\mathrm{R}^{2}$ sebesar 0,9999 yang menunjukkan bahwa 99,99\% titik pada grafik dilalui oleh garis regresi. Sehingga nilai $\mathrm{R}^{2}$ dapat digunakan sebagai indikator bahwa alat rancangan memiliki akurasi yang baik. 


\subsection{Pembahasan}

Pada penelitian ini telah berhasil dirancang alat kontrol ketinggian air menggunakan sensor ultrasonik berbasis SMS. Alat yang dirancang menggunakan ATmega328 sebagai mikrokontroler, sensor ultrasonik HC-SR04, modul GSM SIM800L sebagai penerima dan pembaca SMS, LCD (16 x 2) sebagai display, relay sebagai saklar on/off, step down LM2596 DC-DC sebagai penurun tegangan, serta pompa air. Pengujian dilakukan dengan mengaplikasian sensor pada alat kontrol ketinggian air. Pengujian ini dilakukan dengan cara memberikan perintah pesan teks (SMS) berupa set point yang dikirim melalui ponsel menuju nomor kartu prabayar yang digunakan pada alat rancangan. Untuk memonitoring ketinggian air pada tangki dengan mengirim pesan "STATUS". Gambar 7 merupakan tampilan dari layar ponsel yang digunakan untuk memberi perintah kepada alat rancangan. Kata "STATUS" merupakan perintah untuk meminta status ketinggian air pada saat itu, kemudian ketika dikirimkan maka akan mendapatkan respon pesan teks berisi kalimat "Ketinggian air saat ini: 7,74" yang artinya tinggi air pada saat dilakukan penmgecekan melalui ponsel adalah 7,74 cm. perintah "SET 10" merupakan perintah untuk menyalakan pompa air hingga ketinggian air mencapai $10 \mathrm{~cm}$.

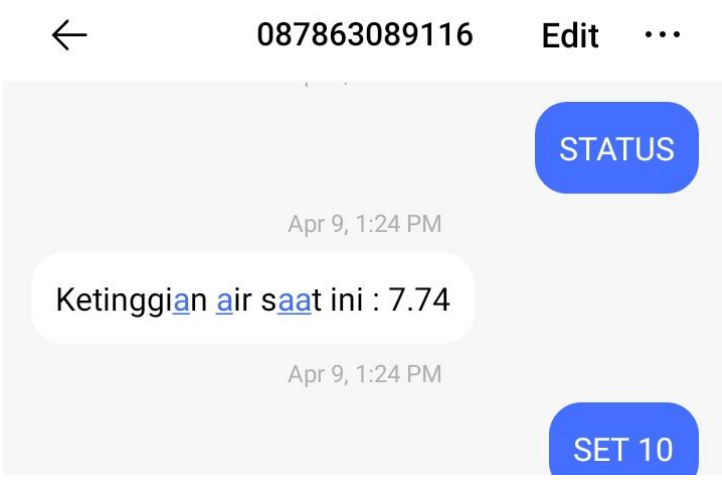

Gambar 7. Contoh perintah penganturan setpoint yang dilakukan oleh ponsel.

Modul SIM800L yang dipasang pada alat rancangan akan menerima SMS yang berisi perintah set point ketinggian air, maka pompa air akan aktif dan mengalirkan air dari sumber air menuju tangki air hingga ketinggian air pada tangki mencapai ketinggian yang diperintahkan set point. Ketika ketinggian air pada tangki telah mencapai tinggi yang sesuai dengan set point maka alat rancangan akan mengirimkan SMS pada pengguna yang berisi keterangan bahwa ketinggian air telah mencapai ketinggian yang diinginkan. Contoh tampilan respon SMS dari alat rancangan dapat dilihat pada Gambar 8.

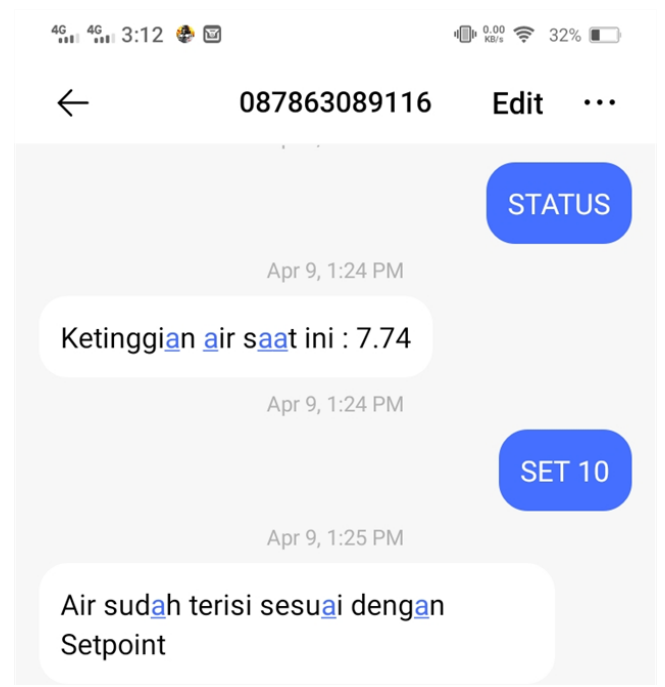

Gambar 8. Tampilan respon dari alat rancangan yang diterima melalui ponsel ketika tinggi air telah mencapai setpoint.

Pengambilan data pengamatan dilakukan penambahan ketinggian air pada tangki setinggi $1 \mathrm{~cm}$ dari 0 $\mathrm{cm}$ hingga mencapai tinggi $60 \mathrm{~cm}$ dan didapat data pengamatan alat rancangan. Pada hasil uji coba 
pengaplikasian sensor pada alat rancangan terdapat perbedaan selisih ketinggian antara alat ukur referensi terhadap alat rancangan, hal ini dikarenakan beberapa faktor yaitu perbedaan persepsi pembacaan pada alat ukur referensi, kelembaban yang berpengaruh pada akurasi sensor ultrasonik. Secara teori yang didapat dari datasheet dari sensor ultrasonik HC-SR04, sensor tersebut dapat bekerja dari rentang jarak 0 $\mathrm{cm}$ hingga $400 \mathrm{~cm}$, namun pada penelitian ini sensor hanya mampu menjangkau jarak sejauh $60 \mathrm{~cm}$. Penyimpangan ini disebabkan oleh media yang digunakan berupa pipa PVC yang tentunya dapat menyerap pancaran gelombang ultrasonik yang dipancarkan oleh sensor. Gekombang ultrasonik yang dipancarkan oleh sensor seharusnya dipantulkan secara sempurna oleh air yang berada dalam tangki, namun gelombang ultrasonik pada penelitian ini dipancarkan dari suatu medium yang kurang rapat (udara) menuju medium yang lebih rapat (permukaan air) maka gelombang tersebut akan sebagian dibiaskan dan dipantulkan. Selain itu sensor ultrasonik ditempatkan tidak secara tegak lurus dan tidak tepat berada di tengah-tengah tangki yang menyebabkan gelombang ultrasonik mengalami pemantulan di dinding tangki sehingga gelombang pantul yang diterima oleh receiver bukan dari pantulan air yang berada di dalam tangki. Kesalahan-kesalahan tersebut menyebabkan pembacaan ketinggian air pada tangki mengalami ketidak akuratan. Dari hasil akurasi alat dapat diindikatorkan bahwa alat yang dirancang dapat digunakan dan bekerja dengan baik.

\section{Kesimpulan}

Berdasarkan pada hasil penelitian yang telah dilakukan maka diperoleh kesimpulan yaitu, telah berhasil dirancang alat kontrol ketinggian air menggunakan sensor ultrasonik berbasis SMS dan Pengujian alat ukur rancangan dilakukan dengan cara membandingkan tinggi air yang dibaca oleh alat ukur rancangan terhadap alat ukur referensi memiliki tingkat akurasi sebesar 99,99\% dan dapat bekerja dengan baik.

\section{Ucapan Terima Kasih}

Penulis menyampaikan terimakasih kepada staf dosen bidang minat Instrumentasi, Elektronika dan Komputasi, Prodi Fisika, FMIPA, UNUD yang telah memberikan saran serta masukan terkait penelitian ini.

\section{Pustaka}

[1] Nurul Zamarudin, Monitoring dan Evaluasi Kualitas Air pada PDAM Area Aceh Besar Bulan April dan Juli, J. of Aceh Phys. Soc. (JAcPS), vol. 7, no. 1, 2018, pp. 39-42.

[2] Farhan, Pengamatan dan Pengendalian Volume Air pada Tangki Menggunakan Sensor Ultrasonik dan Arduino UNO, Jurnal Teknik Fisika Universitas Nasional, 2017.

[3] D. Andesta, R. Ferdian, Sistem Keamanan Sepeda Motor Berbasis Mikrokontroler dan Modul GSM, JITCE(Journal of Information Technology and Computer Engineering), vol. 2, no. 2, 2018, pp. 51-63.

[4] Astari, P. D, Akses Data Menggunakan SMS (Rancang Pengolahan Database Untuk Nilai dan Kompensasi Berbasis Sms (Short Message Service). Tugas Akhir. Palembang: Politeknik Negeri Sriwijaya, 2012.

[5] Slamet Risnanto, Aplikasi Pemungutan Suara Elektronik Menggunakan Teknologi Short Message Service dan ATCommand, Jurnal Tekniki Informatika, vol. 10, no.1, 2017.

[6] Gusmanto, Rancang Bangun Sistem Peringatan Dini Dan Pelacakan Pada Kendaraan Sepeda Motor Dengan Menggunakan Mikrokontroler Arduino Nano, Jurnal Teknik Elektro Universitas Tanjungpura, 2016, vol. 2, no. 1.

[7] J. M. Hamid, Prototype Penyiram Tanaman dan Pengukur Kelembaban Tanah Berbasis Arduino Uno. Jurnal INTEK, vol. 2, no. 2, 2019.

[8] Oimolala Juvenrius, Sistem Pengukuran Temperatur Pada Penggosengan Biji Jagung Berbasis ATMega328 dengan tampilan LCD, Skripsi Universitas Sumatera Utara, 2018.

[9] Siswanto, Pemanfaatan Sensor Suhu DHT-22 dan Sensor Ultrasonik HC-SR04 untuk mengendalikan Kolam dengan Notifikasi Email, Jurnal RESTI (Rekayasa Sistem dan Teknologi Informasi), vol. 3, no. 3, 2019, pp: 544-551.

[10] Dewanto Eki, Tandon Otomatis Dengan Sistem Monitoring melalui Android Berbasis Arduino UNO, Jurnal Autotracy, vol. 5, no. 1, 2018, Jakarta.

[11] M. Saiful, Sistem Monitoring Volume Air Mengunakan Sensor Ultrasonik dan Monitoring Uoutput Volume Air Menggunakan Flowmeter Berbasis Arduino, Jurnal Gema Teknologi vol. 19, no. 2, pp: 
6-9, 2017.

[12] Yusuf, B. H., Pembuatan Alat Ukur Suhu Rendah Berbasis Mikrokontroler Atmega328 Menggunakan Sensor Suhu RTD PT-100, Buletin Fisika, vol. 21, no.1, 2020, pp. 26-23. Universitas Udayana.

[13] Azmi Kurdianto, Rancang Bangun Pengisi Toren Air Otomatis Menggunakan Sensor Inframerah Berbasis Arduino Uno, Prosiding Seminar Nasional Fisika 5.0, 2019. Universitas Pendidikan Indonesia.

[14] Astari, P. D., Akses Data Menggunakan SMS (Rancang Pengolahan Database Untuk Nilai dan Kompensasi Berbasis Sms (Short Message Service). Tugas Akhir. Palembang: Politeknik Negeri Sriwijaya, 2012. 